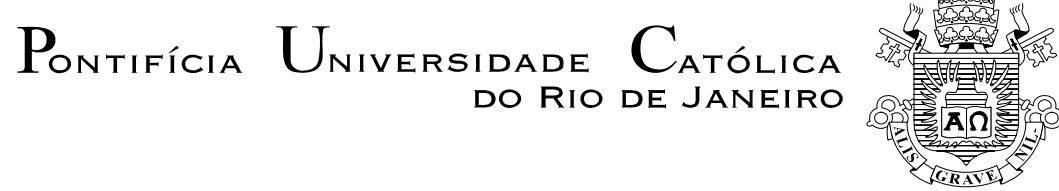

Raquel Brigatte

Práticas narrativas em audiências de conciliação no PROCON

Tese apresentada ao Programa de Pós-graduação em Letras do Departamento de Letras da PUC-Rio como parte dos requisitos parciais para obtenção do título de Doutor em Letras.

Orientadora: Profa. Maria do Carmo Leite de Oliveira

Rio de Janeiro

Janeiro de 2009 


$$
\text { Pontifícia Universidade } \text { Cetólica }_{\text {dato de Janeiro }}
$$

\section{Raquel Brigatte}

\section{Práticas narrativas em audiências de conciliação no PROCON}

Tese apresentada como requisito parcial para obtenção do grau de Doutor pelo Programa de Pós-Graduação em Letras do Departamento de Letras do Centro de Teologia e Ciências Humanas da PUC-Rio. Aprovada pela Comissão Examinadora abaixo assinada.

Profa. Maria do Carmo Leite de Oliveira

Orientadora

Departamento de Letras - PUC-Rio

Profa. Liliana Cabral Bastos

Departamento de Letras - PUC-Rio

Profa. Diana de Souza Pinto

UNIRIO

\section{Profa. Sonia Bittencourt Silveira}

UFJF

Profa. Wânia Terezinha Ladeira

UFV

Prof. Paulo Fernando Carneiro de Andrade

Coordenador Setorial do Centro de Teologia

E Ciências Humanas - PUC-Rio

Rio de Janeiro, 23 de janeiro de 2009 
Todos os direitos reservados. É proibida a reprodução total ou parcial do trabalho sem autorização da autora, da orientadora e da universidade.

\section{Raquel Brigatte}

Graduou-se em Letras na Universidade Federal de Juiz de Fora, em 1997. Concluiu o mestrado na mesma instituição em 2003, estudando o fenômeno da progressão referencial nas audiências de conciliação do PROCON. Ingressou no curso de Doutorado em Letras da PUC-Rio em 2005.

Participou de diversos congressos na área de Estudos de Linguagem.

Ficha Catalográfica

Brigatte, Raquel

Práticas narrativas em audiências de conciliação no PROCON / Raquel Brigatte ; orientadora: Maria do Carmo Leite de Oliveira. - 2009.

196 f. ; $30 \mathrm{~cm}$

Tese (Doutorado em Letras) - Pontifícia Universidade Católica do Rio de Janeiro, Rio de Janeiro, 2009.

Inclui bibliografia

1. Letras - Teses. 2. Audiências de conciliação. 3. Narrativa. 4. Identidade. 5. fala-em-interação. I. Oliveira, Maria do Carmo Leite de. II. Pontifícia Universidade Católica do Rio de Janeiro. Departamento de Letras. III. Título. 
Ao meu filho Lucas, fonte de alegria para a vida e de inspiração para este trabalho. 


\section{Agradecimentos}

À minha orientadora, Professora Maria do Carmo Leite de Oliveira, pela generosa ajuda e pelo carinho com que acompanhou a construção deste trabalho.

À Capes e à PUC-Rio, pelos auxílios concedidos.

À Professora Sonia Bittencourt Silveira, por me permitir a utilização dos dados aqui estudados, pelas valiosas observações feitas no exame de qualificação e pelo apoio de sempre.

À Professora Diana de Souza Pinto, pela amizade e por todos os ensinamentos e estímulos ao longo da minha vida acadêmica.

À Professora Liliana Cabral Bastos, por ter me introduzido no estudo das narrativas e pelas indicações bibliográficas nos cursos e na qualificação.

À Professora Wânia Terezinha Ladeira, por aceitar participar da minha banca.

Aos meus pais, pelo amor incondicional e suporte em todos os momentos da minha vida, e aos meus irmãos, pelo incentivo e companheirismo.

Ao meu marido, pela companhia e amor constantes.

À secretaria do Departamento de Letras, especialmente a Chiquinha, pelo atendimento sempre prestativo.

Aos professores do Departamento de Letras da PUC-Rio, pelos valiosos cursos na área de Estudos de Linguagem. 


\section{Resumo}

Brigatte, Raquel; Oliveira, Maria do Carmo Leite (Orientadora). Práticas narrativas em audiências de conciliação no PROCON. Rio de Janeiro, 2009. 196p. Tese de Doutorado - Departamento de Letras, Pontifícia Universidade Católica do Rio de Janeiro.

Este trabalho investiga as práticas narrativas no discurso de reclamado e reclamante em audiências de conciliação no PROCON de duas cidades do estado de Minas Gerais. Consideramos que o ato de contar estórias circunscrito pelo ambiente PROCON comporta especificidades que o difere, por exemplo, das narrativas observáveis em conversas cotidianas e em outros contextos institucionais. A partir de uma abordagem sócio-interacional para o discurso, de acordo com os pressupostos da Sociolingüística Interacional em interface com a Análise da Conversa, buscou-se observar em que medida as formas e funções que as construções narrativas assumem nas audiências moldam e são moldadas pela institucionalidade do encontro social em foco. Focalizamos em que medida reclamado e reclamante sinalizam orientações diferentes acerca da responsabilidade pela ação danosa, questão esta que perpassa a construção das narrativas no PROCON. Ao longo do percurso narrativo, as partes divergentes se engajam em uma disputa pela definição da situação, articulando manobras discursivas estratégicas no sentido de conferir legitimidade e credibilidade aos seus relatos. Consideramos que a dinâmica de formulações identitárias elaboradas nos relatos via elementos avaliativos está a serviço das intervenções estratégicas a que recorrem os participantes ao darem sentido ao ocorrido. Buscamos demonstrar também como a tarefa institucional exercida pelo mediador no decorrer das audiências revela-se decisiva para o desenvolvimento das práticas narrativas e para a construção e negociação da definição da situação.

\section{Palavras-chave}

Audiências de conciliação; narrativa; identidade; fala-em-interação. 


\section{Abstract}

Brigatte, Raquel; Oliveira, Maria do Carmo Leite (Advisor). Narrative practices in conciliation hearings at PROCON. Rio de Janeiro, 2009. 196p. Ds. Thesis - Departamento de Letras, Pontifícia Universidade Católica do Rio de Janeiro.

This work investigates narrative practices developed by complainant and complainer in conciliation hearings at PROCON from two cities of Minas Gerais State. We assume that the storytelling framed by this setting has some characteristics that differs for example from the narratives told in spontaneous and other institutional contexts. Based on the intersection between Interactional Sociolinguistics and Ethnomethodological conversation analysis, we examine how shapes and functions of narrative constructions in this setting build and are built by the institutionality of the interaction. We focused on how complainant and complainer show different orientations about the responsibility for that damaging action, which is very present on narrative constructions at PROCON. Throughout narrative development, the disputants engage on a dispute over the definition of the situation making use of discourse strategies in order to present legitimacy and credibility to their narrations. We consider that the dynamic of identity formulations developed during narrations through evaluation elements is focused on strategic interventions used by the participants to shape their meanings about the facts. We also examine how the mediator's institutional task during hearings is crucial for the development of narrative practices and construction and negotiation of the definition of the situation.

\section{Keywords}

Conciliation hearings; narrative; identity; talk-in-interaction. 


\section{Sumário}

1. INTRODUÇÃO 11

1.1. Definição do problema $\quad 13$

$\begin{array}{lr}\text { 1.2. Perguntas de pesquisa } & 15\end{array}$

$\begin{array}{ll}\text { 1.3. Objetivos } & 15\end{array}$

$\begin{array}{ll}\text { 1.4. Justificativa e relevância da pesquisa } & 17\end{array}$

2. A PERSPECTIVA SOCIOINTERACIONAL 21

2.1. Pistas de contextualização 24

2.2. Enquadres $\quad 27$

2.3. Alinhamentos e posicionamentos 29

2.4. Estrutura de participação $\quad 32$

2.5. As explicações como movimento corretivo 34

2.6. A elaboração da face $\quad 35$

2.7. A fala-em-interação em cenários institucionais 39

2.7.1. A fala-em-interação no PROCON 42

3. TEMAS DA PESQUISA

3.1. A reclamação $\quad 45$

3.2. As narrativas 48

3.2.1. Estrutura das narrativas: a contribuição de Labov 52

3.2.2. A contribuição de Sacks $\quad 59$

3.2.3. Narrativa e experiência 61

3.2.4. A performance da experiência $\quad 62$

3.2.5. Narrativa e identidade 64

4. AS NARRATIVAS NOS CONTEXTOS JURÍDICOS E NO PROCON $\quad 67$

4.1. Tribunal: contexto e processo narrativo $\quad 67$

4.2. Plea bargaining: contexto e processo narrativo $\quad 74$

4.3. Juizados Especiais: contexto e processo narrativo 77

4.4. O estudo das narrativas no PROCON 81

5. PRESSUPOSTOS METODOLÓGICOS

5.1. A natureza da pesquisa $\quad 83$

5.2. A unidade de serviço em estudo: o PROCON 85

$\begin{array}{ll}\text { 5.2.1. O PROCON e o CDC } & 90\end{array}$

5.2.2. O PROCON de Juiz de Fora 91

$\begin{array}{ll}\text { 5.2.3. As audiências de conciliação } & 94\end{array}$

5.3. A pesquisa em torno da fala-em-interação no PROCON 97

5.3.1. Gravação e transcrição de dados 98

5.4. O material lingüístico analisado $\quad 100$

5.4.1. A audiência de conciliação Conrado 101

5.4.2. A audiência de conciliação OK Veículos 101 
6. PRÁTICAS NARRATIVAS NO AMBIENTE PROCON 103

6.1. A natureza da reclamação 103

6.2. O processo narrativo na $1^{\text {a }}$ fase 107

6.2.1. O resumo do mediador 109

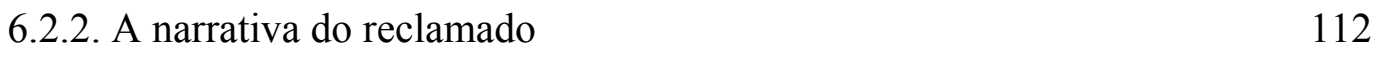

$\begin{aligned} & \text { 6.2.2.1. Avaliações e projeções de identidade elaboradas pelo } \\ & \text { reclamado }\end{aligned}$
116

6.2.3. A narrativa do reclamante 119

6.2.3.1. Avaliações e projeções de identidade elaboradas pelo
reclamante

6.3. O processo narrativo na $2^{\mathrm{a}}$ fase $\quad 130$

6.3.1. A negociação da responsabilidade $\quad 133$

6.3.2. As manobras do mediador $\quad 140$

6.3.2.1. Evocando o CDC 141

$\begin{array}{ll}\text { 6.3.2.2. Gerenciando o conflito } & 145\end{array}$

$\begin{array}{ll}\text { 7. CONSIDERAÇÕES FINAIS } & 149\end{array}$

8. REFERÊNCIAS BIBLIOGRÁFICAS 157

9. ANEXOS

168 
TABELA DE CONVENÇÕES PARA TRANSCRIÇÃO

\begin{tabular}{|c|c|}
\hline [colchetes] & fala sobreposta. \\
\hline (0.5) & pausa em décimos de segundo. \\
\hline$()$. & micropausa de menos de dois décimos de segundo \\
\hline$=$ & $\begin{array}{l}\text { contigüidade entre a fala de um mesmo falante ou de dois falantes } \\
\text { distintos. }\end{array}$ \\
\hline - & descida de entonação. \\
\hline$?$ & subida de entonação. \\
\hline , & entonação contínua. \\
\hline$?$ & $\begin{array}{l}\text { subida de entonação mais forte que a vírgula e menos forte que o } \\
\text { ponto de interrogação. }\end{array}$ \\
\hline$:$ & alongamento de som. \\
\hline- & auto-interrupcão. \\
\hline Su blinhado & acento ou ênfase de volume. \\
\hline MAIUSCULA & ênfase acentuada. \\
\hline 0 & fala mais baixa imediatamente após o sinal. \\
\hline${ }^{\circ}$ palavras $^{0}$ & trecho falado mais baixo. \\
\hline palavra : & descida entoacional inflexionada. \\
\hline palavra: & subida entoacional inflexionada. \\
\hline$\uparrow$ & $\begin{array}{l}\text { subida acentuada na entonação, mais forte que os dois pontos } \\
\text { sublinhados. }\end{array}$ \\
\hline$\downarrow$ & $\begin{array}{l}\text { descida acentuada na entonação, mais forte que os dois pontos } \\
\text { precedidos de sublinhado. }\end{array}$ \\
\hline palavras $<$ & fala comprimida ou acelerada. \\
\hline <palavras > & desaceleração da fala. \\
\hline <palavras & início acelerado. \\
\hline hhh & aspirações audíveis. \\
\hline (h) & aspirações durante a fala. \\
\hline hhh & inspiração audível. \\
\hline$(())$ & comentários do analista. \\
\hline (palavras) & transcrição duvidosa. \\
\hline () & transcrição impossível. \\
\hline “palavras” & diálogo construído. \\
\hline
\end{tabular}

Convenções baseadas nos estudos da Análise da Conversa (Sacks, Schegloff e Jefferson, 1974; Atkinson e Heritage; 1984), incorporando símbolos sugeridos por Schiffrin (1987), Tannen (1989) e Gago (2002). 